\title{
Responses of the Internal and External Economic Conditions to Exchange Rate Regimes in Nigeria: The Comparative Analysis
}

\author{
Lee Lee N. Deekor (Corresponding author) \\ Department of Economics, Ignatius Ajuru University of Education, \\ Port Harcourt, Nigeria. \\ E-mail: leeleenwiibari@yahoo.com
}

Received: January 24, 2022 Accepted: February 25, 2022 Published: March 2, 2022

doi: 10.5296/jsss.v9i1.19613

URL: https://doi.org/10.5296/jsss.v9i1.19613

\begin{abstract}
Exploring the ARDL modeling techniques, this study hypothesized that the internal and external economic conditions respond differently to exchange rate regimes. Covering the period between 1970 and 2020, the study shows that both fixed regime and intermediate regimes have the potential of causing declining inflation (INFL) compared to floating exchange rate regimes. However, when the economic condition is considered from the external perspective measures using trade balance, the magnitude of the impact of both fixed and intermediate regimes appears to be relatively higher for the external economic condition (trade balance) compared to inflation which is a measure for internal economic condition. More importantly, our findings tend to find support in a number of the previous studies.
\end{abstract}

Keywords: exchange rate regimes, economic performance, ARDL, Nigeria

\section{Introduction}

The exchange rate is a relative price upon which the competitiveness of a country's exchange power vis-à-vis the foreign currencies is usually reflected. Saying it differently, the phenomenon 'exchange rate' serves as an anchor which supports sustainable internal and external macroeconomic balances over the medium-term to long-term. Consequently, there has been increasing efforts to understand not only the dynamics of exchange rate management but also its economic implications. Essentially, the quest for an effective exchange rate management has been the essence of literature on the impact of exchange rate regime on economic performance both on the part of policymakers and the academics. That said, quite a number of the extant studies on the subject matter has continued to focus mainly on the internal 
indicators of economic condition. Whereas, the economic implications of exchange rate regimes are not only internal but also external. To this end, both the theoretical and empirical efforts in the literature towards resolving the question of whether or not there exists a link between a country's economic performance and exchange rate regimes has continued to produce mixed results.

Beyond differences in the investigated economies, sample coverage, methods, among other; what constitutes innovation in this study is whether the internal and external economic conditions respond differently to exchange rate regimes. Also, the choice of Nigeria as the investigated economy is motivated by the hypothesis that close-up evaluation of individual countries is likely to provide a much keener guide as to the dynamics and ultimate outcome of policy choice on exchange rate management. More importantly, both the internal and external economic conditions in Nigeria have been rather abysmal despite the effort of the government in using the exchange rate as a stabilization effort for the economy.

In view of the above, the innovation in the context of this study is to test whether the viability or otherwise of exchange rate regimes for explaining economic performance in Nigeria varies for internal compared to external indicators of macroeconomic conditions. Compared to a number of the previous studies, the empirical finding based on this study will provide the policymakers with evidence -based insights on how to avoid running into exchange rate policy erroneous that might result from generalizing the dynamics of the impact of exchange rate regimes on internal and external economic conditions.

In addition to this introductory section, the rest of the paper is structured as follows: Section 2 presents a brief literature review. Section 3 discusses the data and presents the methodology. Section 4 presents the results and discusses the findings while section 5 concludes the paper.

\section{Review of Previous Studies}

While examining the impact of exchange rate regime on growth of 60 industrialized and developing countries, Bailliu et al. (2003) utilizes dynamic GMM panel estimation technique to show that there is a positive link between fixed exchange rate regimes and economic growth. Finding from the study further suggests that an intermediate regime without an anchor is negatively associated with economic growth, while all other regime types were reported to have exhibited no discernible impact on economic growth. For Husain et al. (2005), they estimate (with and without fixed country effects) exchange rate regime durability and performance across a large panel of advanced, emerging and developing economies. They find that in developing countries more flexible regimes are associated with high inflation but do not lead to gains in output growth while fixed or near fixed regimes deliver lower inflation without sacrificing growth.

In attempt to replicate the LYS growth regressions, Miles (2006) considered the case of a developing countries' subset of the LYS original sample and concludes, that once a measure of domestic distortions is added to the model, exchange rate regimes exert no independent impact on the output growth of developing countries. Bleaney \& Francisco (2007) also considered the case study of developing countries across using official (IMF) and four alternative de facto 
exchange rate regime classifications. The study finds that floats have very similar growth rates to 'soft' (easily adjustable) pegs while 'hard' pegs (currency unions and currency boards) have slower growth than other regimes. The only exception to this position according to the study is when the estimates are obtained from the Reinhart \& Rogoff (2004) regime classification, which according to the authors produces quite unfavorable outcomes for flexible regimes (higher inflation and lower growth).

Raji (2013) investigates the impact of exchange rate misalignment on economic performance in the WAMZ using GMM estimation technique. The outcome of the study revealed that the WAMZ is exposed to asymmetrical correlation between real exchange rate misalignment and economic performance. Using the Bayesian Model of Averaging (BMA) technique to investigate the relevance of exchange rate regime in restraining current account imbalance in Sub-Saharan African nations, Gnimassoun (2015) shows that flexible exchange rate regimes are more effective in preventing disequilibria. In a similar development, Nathaniel et al. (2019) investigate the impact of exchange rate regimes on economic integration in the ECOWAS using the econometric technique of panel fixed effect model. The study found that exchange rate regimes have the potential to deepen economic integration in the ECOWAS.

Notable among the previous studies in the context of the Nigerian economy includes Adeoye \& Atanda (2010); Omojimite \& Akpokodje (2010); Mahmood \& Ali (2011); Dada \& Oyeranti (2012); Adesoye (2012); among others. However, there have been little or no concrete efforts to unravel the extent to which the impact of exchange rate regimes on economic performance is likely to vary for internal economic activities compared to the external economic conditions. Motivated by this concern, this present study hypothesized that the impacts of exchange rate regimes on economic performance varies for different indicators of macroeconomic conditions, particularly from the perspectives of internal and external macroeconomic indicators.

\section{Methodology and Data}

\subsection{Model Specification}

Starting with the internal economic condition which in the context of this study is captured via inflation, we follow the Batini and Haldane (1999) to utilize a reduced-form Phillips curve model which is derived from a combination of mark-ups, wage-contracting and consumption price index equations. The mark-up and wage contracting equations are used to represent the supply side of the model based on the staggered contract theory (Fuhrer and Moore, 1995; Buiter and Jewitt, 1981) while domestic and foreign goods prices are combined into a consumption price index. This combination yields an aggregate supply (Phillips curve) or price-setting equation which characterizes the dynamic response of inflation to the output gap. The final specification is an open-economy aggregate supply equation that depicts inflation as a function of its own lagged values (backward-looking inflation), output gap (representing current mark-up of firms' prices over marginal costs) and real exchange rate changes (reflecting the price effects of exchange rate changes on imported goods). This is represented by equation (1). 


$$
I N F L=\beta_{0} * I N F L_{t-1}^{\beta_{1}} * Y G^{\beta_{2}} * E X R^{\beta_{3}} * e^{\mu}
$$

Again, equation (1) is further extended to capture the impact of the exchange rate regime on economic performance via the inflation rate channel.

$$
I N F L=\beta_{0} * I N F L_{t-1}^{\beta_{1}} * Y G^{\beta_{2}} * E X R^{\beta_{3}} * R G M^{\beta_{4}} * e^{\mu}
$$

The natural logarithm variant of the extended inflation model in equation (2) is as given below.

$$
\log I N F L_{t}=\beta_{0}+\beta_{1} \log I N F L_{t-1}+\beta_{2} \log Y G_{t}+\beta_{3} \log E X R_{t}+\beta_{4} \log R G M_{t}+\varepsilon_{t}
$$

The inclusion of the lagged value of inflation represents the short-run trade-off between

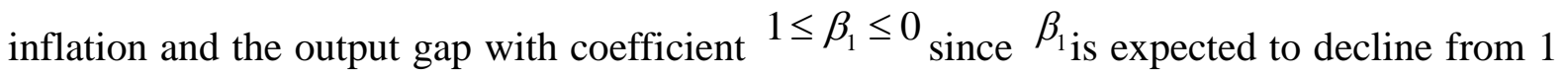
with the relative importance of backward-looking expectations. In other words, when it is close to 0 , inflation responds to its past values and therefore, may take some periods for the accumulated effect of monetary policy to affect inflation. The closer it is to 1 , the more will a small, but persistent increase in interest rates have a huge and instant impact on current inflation.

The equation also recognizes that interest rate affects inflation via the current and past outputs.

The coefficient $\beta_{2}$ on the output gap is expected to decline in a situation when adaptive expectations are more important. This is because the output gap also operates via its expected price movements (Berg et al., 2006). The inclusion exchange rate changes originate from the afore-mentioned mark-up, wage-contract and consumption price index equations. Thus, the coefficient on exchange rate is expected to be positive but depending on the relatively openness of the economy.

To further explore the potential of exchange rate regimes impacting the economic performance differently from the perspective of the external activity of the economy, this study follows the balance of trade channel. The balance of trade herein is measured as exports less imports of visible goods. The nexus between trade balance and exchange rate is usually anchored on the assumption that neither imports or exports are a perfect substitute for domestic goods. More so, the economy consists of two goods; home and foreign goods and part of home goods is exported and part of foreign goods is also demanded by domestic consumers. Consequently, the trade balance (TB) can be expressed as a function of foreign income (FY), domestic income, (DY), exchange rate (EXR), and trade openness (TOP). Thus, the functional representation of the trade balance model is given as follows:

$$
T B=f(F Y, D Y, E X R, T O P)
$$

The estimable and econometric representation of the above functional relational is further represented in natural logarithm form as below. 
$\log T B_{t}=\beta_{0}+\beta_{1} \log F Y_{t}+\beta_{2} \log D Y_{t}+\beta_{3} \log E X R_{t}+\beta_{4} \log T O P_{t}+\varepsilon_{t}$

To capture the extent to which exchange rate regime matters for trade balance, equation (5) is further modified and extended as below.

$$
\log T B_{t}=\beta_{0}+\beta_{1} \log F Y_{t}+\beta_{2} \log D Y_{t}+\beta_{3} \log E X R_{t}+\beta_{4} \log T O P_{t}+\beta_{5} R G M_{t}+\varepsilon_{t}
$$

\subsection{Variable Description and Data Source}

All data used for this study are annual time series covering the period between 1970 and 2020 . The data were obtained from secondary sources including Central Bank of Nigeria (CBN) online databases, CBN annual statistical bulletin, and World Development Indicators (WDI) online database. The key variables of interest include, inflation (INFL) measured as log of consumer price index, and trade balance (TB) measured as log of exports less log of imports of visible goods. In addition, exchange rates (EXR) are measured as the log of the country's national currency (Naira) relative to the dollar which was captured in each of the models. We also control for other variables depending on the model under consideration.

Regarding the model for internal economic conditions for example, we control for the level of income measured as log of real GDP per capita and represented as (YG), while domestic income (DY) and foreign income (FY) are included in the model for external economic conditions. The former is measured as log of Nigeria's real GDP while the latter is measured as $\log$ of world real GDP less log of Nigeria's real GDP.

On the measures for exchange rate regimes, there are at least eight categories of foreign exchange regimes irrespective of the regimes classification scheme that is under consideration, ranging from currency union at one corner to free floating at second corner: pegged (hard pegs, conventional pegs, horizontal bands), intermediate regimes (crawling pegs, crawling bands, target zones), and floating arrangements (free floats, managed floats). Consequently, the dummies for exchange rate regimes in the context of this study were classified into three major groups namely, pegged/fixed regime (FIX), intermediated regime (INTER) and floating/flexible regime (FLEX).

Essentially, the dummies take the value of one if a specific exchange rate regime prevailed in a given period, and zero if otherwise. Saying it differently, for both the statistical and non-statistical approach to exchange rate regime classification, we create dummies for pegged/fixed, intermediate (INTER), and floating/flexible (FLEX) exchange rate regimes, and but the later (i.e. FLEX) was reflected as the default benchmark. The essence is to avoid running into the problem of a dummy trap and to also understand the extent to which economic performance has been responding differently to different groups of exchange rate regimes.

\subsection{Econometric Technique}

In order to accommodate both short and long run dynamics of the variable of interests, the Auto-regressive Distributed Lag (ARDL) modelis considered the most appropriate in the context of this study. The bias for ARDL compared to other alternative methods in the literature 
is motivated by its flexibility regardless of whether the variables under consideration are stationary or become stationary after being different. According to Pesaran et al. (2001), the selection of the optimum ARDL model involves automatic correction of the residual serial correlation and of the endogeneity problem. Thus, the ARDL representation of the nexus between economic performance and exchange rate regime is as given below.

$$
\Delta \ln Z_{t}=\varphi+\alpha_{1} \ln Z_{t-1}+\alpha_{2} \ln X_{t-1}+\alpha_{3} \ln E X R_{t-1}+\sum_{j=1}^{p} \beta_{1 j} \Delta \ln Z_{t-j}+\sum_{i=0}^{q 1} \beta_{2 i} \Delta \ln X_{t-i}+\sum_{i=0}^{q 2} \beta_{3 i} \Delta \ln E X R_{t-i}+\sum_{n=1}^{k} \lambda_{n} D_{n t}+\varepsilon_{t}
$$

Where $Z$ is a vector denoting economic condition to be captured singly via both internal and external measures of economic activities such as inflation rate (INFL) and trade balance (TB), respectively. The term $X$ is a set of exogenous variables depending on which measure of economic conditions is being considered. EXR represents the exchange rate with US dollar, the reference currency while $D$ is a matrix representing a dummy variable for exchange rate regime type to be captured as fixed regressor(s).

The long run parameters for the intercept and slope coefficients are computed as: $-\frac{\varphi}{\alpha_{1}},-\frac{\alpha_{2}}{\alpha_{1}}$ and $-\frac{\alpha_{3}}{\alpha_{1}}$. However, since in the long run it is assumed that $\Delta Z_{t-j}=0$ and $\Delta(X, E X R)_{t-i}=0$, respectively, then the short run estimates are obtained as $\beta_{1 j}, \beta_{2 i}$ and $\beta_{3 i}$. Since the variables in first differences can accommodate more than one lag, determining the optimal lag combination for the ARDL becomes necessary. The optimal lag length is selected using Schwartz Information Criterion (SIC).

The lag combination with the least value of the chosen criterion among the competing lag orders is considered the optimal lag. Consequently, the preferred ARDL model is used to test for long run relationships in the model. This approach of testing for cointegration as earlier described is referred to as bounds testing as it involves the upper and lower bounds. The test follows an $F$ distribution such that, if the calculated F-statistic is greater than the upper bound, there is cointegration; if it is less than the lower bound, there is no cointegration and if it lies in between the two bounds, then, the test is considered inconclusive. Equation (7) can be re-specified to include an error correction term as follows:

$$
\Delta \ln Z_{t}=\varphi+\delta E C T_{t-1}+\sum_{j=1}^{p} \beta_{1 j} \Delta \ln Z_{t-j}+\sum_{i=0}^{q 1} \beta_{2 i} \Delta \ln X_{t-i}+\sum_{i=0}^{q 2} \beta_{3 i} \Delta \ln E X R_{t-i}+\sum_{n=1}^{k} \lambda_{n} D_{n t}+\varepsilon_{t}
$$

Equation (8) is the error correction variant of the ARDL model in equation (7), where the $E C T_{t-1}$ is the error correction term while the coefficient $\delta$ represent the speed of adjustment to 
equilibrium level. If the value of the coefficient is in the $(-1,0)$ range, then the error correction mechanism is stable and ECT helps to adjust the long-run relationship due to the impact of a

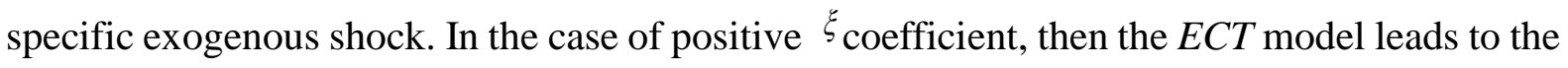
model deviation from the long-run equilibrium so that a certain shock will no longer be neutralized.

If those ratios are closer to 0 , then the exogenous shock adjustment is performed at low speed, while the closeness to -1 corresponds to a high shock adjustment in one period taken into account (for example, one year in the case of annual data, a quarter for quarterly data etc.). It is instructive that the term $D$ which is a matrix of dummy variables for fixed (FIX), intermediate (INTER) and flexible (FLEX) exchange rate regime types will be capture as fixed regressors with the latter (i.e. FLEX) suppressed from the estimation to avoid perfect collinearity problems.

\section{Result Presentation and Discussion}

\subsection{Preliminary Results}

A cursory look at Table 1 shows that the mean statistic puts the average consumer price index a measure for inflation (INFL) in Nigeria at 52.81 between the period 1970 and 2020, while the mean value for trade balance (TB) is positive, which is an indication that the country has been maintaining a trade surplus on average over period between 1970 and 2020.As a precondition for most time series analyses, this study also conducts unit root tests on all the variables under consideration and the essence is to determine the stationary status of the series and in turn the suitability of the chosen estimation techniques. Starting with the ADF results in Table 2, the null hypothesis of unit root tends to hold for a number of the variables with TBand TOP the few notable exceptions, particularly when the ADF test was performed with the model with constant only. Same as the ADF results, the unit root test results obtained from the DF-GLS test also revealed the integration properties of the series to hover between $\mathrm{I}(0)$ and $\mathrm{I}(1)$.

Table 1. Descriptive/Summary Statistics

\begin{tabular}{ccccccccc}
\hline & Mean & Max. & Min. & Std. Dev. & $\begin{array}{l}\text { N-Std. } \\
\text { Dev. }\end{array}$ & Skewness & Kurtosis & J-B \\
\hline INFL & 52.81 & 294.88 & 0.10 & 76.74 & 1.45 & 1.65 & 4.85 & $30.28(0.00)$ \\
$\boldsymbol{T B}$ & 1.04 & 3.19 & -1.17 & 1.20 & 1.16 & 0.27 & 2.01 & $2.71(0.26)$ \\
$\boldsymbol{E X \boldsymbol { R }}$ & 78.25 & 307.76 & 0.55 & 95.57 & 1.22 & 1.09 & 3.20 & $10.17(0.01)$ \\
$\boldsymbol{Y G}$ & 220.79 & 487.47 & 94.69 & 127.72 & 0.58 & 0.99 & 2.42 & $9.12(0.01)$ \\
$\boldsymbol{T O P}$ & 33.32 & 53.28 & 9.14 & 11.91 & 0.36 & -0.46 & 2.33 & $2.78(0.25)$ \\
$\boldsymbol{F Y}$ & 46481 & 86338 & 19117 & 19739 & 0.42 & 0.44 & 1.99 & $3.83(0.15)$ \\
\hline
\end{tabular}

Note: The terms Min in the table denotes Minimum statistic, Max means Maximum, Std. Dev. denotes standard deviation while N-Std. Dev. is the normalized variant of the standard deviation statistic computed as: standard deviation/mean. The values in parenthesis are probability values associated with the reported Jaque-Bera (JB) statistics. 
Table 2(a). ADF unit root test results

\begin{tabular}{|c|c|c|c|c|c|c|}
\hline \multirow[b]{2}{*}{ Variable } & \multicolumn{3}{|c|}{ Model with Constant } & \multicolumn{3}{|c|}{ Model with Constant \& Trend } \\
\hline & Level & First Difference & $\mathbf{I}(\mathbf{d})$ & Level & First Difference & $\mathbf{I}(\mathbf{d})$ \\
\hline INFL & -1.384 & $-4.099 * * *$ & $\mathrm{I}(1)$ & -1.519 & $-4.272 * * *$ & $\mathrm{I}(1)$ \\
\hline$T B$ & $-2.612 *$ & - & $\mathrm{I}(0)$ & -2.575 & $-7.322 * * *$ & $\mathrm{I}(1)$ \\
\hline$E X R$ & -0.363 & $-5.618 * * *$ & $\mathrm{I}(1)$ & -1.444 & $-5.555^{*}$ & $\mathrm{I}(1)$ \\
\hline$Y G$ & 0.600 & $-2.297 * * *$ & $\mathrm{I}(1)$ & 1.429 & $-2.486 * * *$ & $\mathrm{I}(1)$ \\
\hline TOP & $-2.866^{*}$ & - & $\mathrm{I}(0)$ & -2.827 & $-7.871 * *$ & $\mathrm{I}(1)$ \\
\hline$F Y$ & -1.761 & $-5.354 * *$ & $\mathrm{I}(1)$ & $-4.494 *$ & - & $\mathrm{I}(0)$ \\
\hline \multicolumn{7}{|c|}{ Table 2(b): DF-GLS unit root test results } \\
\hline INFL & 0.420 & $-4.146 * * *$ & $\mathrm{I}(1)$ & -1.701 & $-4.343 * * *$ & $\mathrm{I}(1)$ \\
\hline$Y G$ & 1.294 & $-2.072 * * *$ & $\mathrm{I}(1)$ & -1.377 & -2.695 & $\mathrm{I}(1)$ \\
\hline$T B$ & $-2.496 * *$ & - & $\mathrm{I}(0)$ & -2.579 & $-7.445^{* * *}$ & $\mathrm{I}(1)$ \\
\hline$E X R$ & 0.374 & $-5.427 * * *$ & $\mathrm{I}(1)$ & -1.314 & $-5.616 * * *$ & $\mathrm{I}(1)$ \\
\hline$Y G$ & 1.294 & $-2.072 * * *$ & $\mathrm{I}(1)$ & -1.377 & -2.695 & $\mathrm{I}(1)$ \\
\hline TOP & $-2.413 * *$ & - & $\mathrm{I}(0)$ & -2.777 & $-7.937 * * *$ & $\mathrm{I}(1)$ \\
\hline$F Y$ & 0.868 & $-4.867 * * *$ & $\mathrm{I}(1)$ & -2.711 & $-5.506 * * *$ & $\mathrm{I}(1)$ \\
\hline
\end{tabular}

Note: The exogenous lags are selected based on Schwarz info criteria while ****,**,* imply that the series is stationary at $1 \%, 5 \%$ and $10 \%$ respectively. The null hypothesis is that an observable time series is not stationary (i.e., has unit root).

\subsection{Regression Results}

The focal point of this study is to test whether exchange rate regimes impact internal and external economic conditions differently. Starting with the Bound cointegration testing results, the null hypothesis of no cointegration was significantly rejected at $1 \%$ in Tables 3 where economic condition is captured internally via inflation. However, the null hypothesis of no cointegration was also rejected but at $5 \%$ levels of significance when the economic condition was explored externally via trade balance (see Table 4). Conform to the bound cointegration testing results were the coefficients on the Error Correction Term (ECT) reported in each of the Tables. For instance, irrespective of whether the economy is captured internally or externally, the coefficients on the ECT are correctly signed and statistically significant at $1 \%$ level of significance.

Table 3. ARDL estimates on the impact of exchange rate regimes on inflation

\begin{tabular}{cccc}
\hline & \multicolumn{3}{c}{ Dependent variable: Inflation (INFL) } \\
\cline { 2 - 4 } Long Run Equation & Coefficient & Standard Error & T-statistic \\
\hline$Y G$ & -0.4353 & 1.0207 & -0.4265 \\
EXR & & & 5.0457 \\
\hline Short Run Equation & $0.0960^{* * *}$ & 0.1903 & 0.9158
\end{tabular}


$\Delta I N F L_{t-1}$

$-0.0779 * *$

0.0352

$-2.2166$

$\Delta Y G$

$-0.0339$

0.0713

$-0.0475$

$\triangle E X R$

$0.0748 * *$

0.0339

2.2067

$E C T_{t-1}$

Fixed Regressors

Pegged / Fixed (FIX)

$-0.2218 * * *$

0.0661

$-3.3574$

Intermediate(INTER)

$-0.0504 *$

0.0277

$-1.8202$

\begin{tabular}{|c|c|c|c|}
\hline \multicolumn{4}{|c|}{ Bound Test Cointegration Results } \\
\hline Level of Significance & F-statistic & $\mathrm{I}(0)$ & $\mathrm{I}(1)$ \\
\hline $10 \%$ & & 2.63 & 3.35 \\
\hline $5 \%$ & $5.23 * * *$ & 3.10 & 3.87 \\
\hline $1 \%$ & & 4.13 & 5.00 \\
\hline \multicolumn{4}{|c|}{ Diagnostic and Post-Estimation Results } \\
\hline Adjusted $\mathrm{R}^{2}$ : & & & \\
\hline F-statistics: & & & \\
\hline Autocorrelation test (Q-Statistic): & & & \\
\hline Heteroscedasticity test (ARCH LM) & & & \\
\hline Normality test (Jaque-Bera): & & & \\
\hline
\end{tabular}

Note: The value in parenthesis represent the probability values for the various post estimation tests performed, while $* * *, * *$ and $*$ denote $1 \%, 5 \%$ and $10 \%$ level of significance.

Haven confirmed the long run potential of the response of both the internal and external measures of economic conditions to exchange rate regimes, the study then proceeds to analyze and discuss the elasticities of the coefficients. Starting with Table 3, the coefficients on the impact of exchange rate regime on inflation was -0.22 for fixed regime compared to floating regime and -0.05 for intermediate regime compared to floating regime. However, the impact was statistically significant at $1 \%$ for the fixed regime and at $10 \%$ for the intermediate regime. In addition to the lagged value of inflation, other determinants of inflation whose coefficients were also reported in the Table 3 are level of income (YG) and exchange rate (EXR). But the probable impact of these other factors on inflation appears to be only statistically significant in the case of coefficients on EXR which are 0.096 and 0.075 in the long run and short run, respectively. 
Table 4. ARDL estimates on the impact of exchange rate regime on trade balance

\begin{tabular}{|c|c|c|c|}
\hline \multirow[b]{2}{*}{ Long Run Equation } & \multicolumn{3}{|c|}{ Dependent variable: Trade Balance (TB) } \\
\hline & Coefficient & Standard Error & T-statistic \\
\hline$F Y$ & 2.2039 & 4.0463 & 0.5446 \\
\hline$D Y$ & $-3.1197 *$ & 1.6419 & -1.9000 \\
\hline$T O P$ & 0.0302 & 0.0242 & 1.2455 \\
\hline$E X R$ & 0.4406 & 0.4835 & 0.9111 \\
\hline \multicolumn{4}{|l|}{ Short Run Equation } \\
\hline Constant & -5.0908 & 18.8844 & -0.2696 \\
\hline$\Delta T B_{t-1}$ & $-0.5352 * * *$ & 0.1255 & -4.2652 \\
\hline$\Delta F Y$ & 1.1794 & 2.1049 & 0.5603 \\
\hline$\Delta D Y$ & $-1.6696 * *$ & 0.7957 & -2.0983 \\
\hline$\triangle T O P$ & 0.0161 & 0.0123 & 1.3138 \\
\hline$\Delta E X R$ & 0.2358 & 0.2717 & 0.8679 \\
\hline$E C T_{t-1}$ & $-0.5352 * * *$ & 0.1032 & -5.1861 \\
\hline
\end{tabular}

\section{Fixed Regressors}

Pegged / Fixed (FIX)

$1.6711 * * *$

0.5464

3.0583

Intermediate(INTER)

$1.1206^{* * *}$

0.2675

4.1898

\begin{tabular}{cccc}
\hline \multicolumn{3}{c}{ Bound Test Cointegration Results } & \\
\hline Level of Significance & F-statistic & $\mathrm{I}(0)$ & $\mathrm{I}(1)$ \\
$10 \%$ & & 2.20 & 3.09 \\
$5 \%$ & $4.01^{* *}$ & 2.56 & 3.49 \\
$1 \%$ & & 3.29 & 4.37 \\
\hline
\end{tabular}

Diagnostic and Post-Estimation Results

\begin{tabular}{ll}
\hline Adjusted $\mathrm{R}^{2}$ & 0.60 \\
F-statistics & $11.333(0.000)$ \\
Autocorrelation test (Q-Statistic) & $2.658(0.753)$ \\
Heteroscedasticity test (ARCH LM) & $0.398(846)$ \\
Normality test (Jaque-Bera) & $7.465(0.239)$ \\
\hline
\end{tabular}

Note: The value in parenthesis represent the probability values for the various post estimation tests performed, while $* * * * *$ and $*$ denote $1 \%, 5 \%$ and $10 \%$ level of significance. 
In what appears to be confirming our hypothesis that the internal and the external economic conditions respond differently to exchange rate regimes, the empirical estimates in Table 4 showed that the magnitude of the coefficients on the impact of exchange rate regimes is relatively higher and significantly more pronounced when the economic condition is measure from the external perspective using trade balance (TB). For instance, the coefficient on for fixed regime was 1.67 and statically significant at $1 \%$ level while that of intermediate regime was 1.12 and also statistically viable at $1 \%$ level of significance. Compared to the floating regime, both fixed regime and intermediate regime has the potential of increasing the net trade balance of the country positively by $1.67 \%$ and $1.12 \%$, respectively. Same as the lagged value of the TB, the coefficient on domestic income (DY) is negative both in the long run and short run but only statistically significant in the short run with the potential of increasing negative net trade balance by $1.70 \%$.

\section{Concluding remark}

Using historical dataset spanning between 1970 and 2020 in the context of the Nigerian economy, this study utilizes the ARDL modeling techniques to determine whether the internal and external economic conditions respond differently to exchange rate regimes. The study shows that both fixed regime and intermediate regimes have the potential of causing declining inflation (INFL) compared to floating exchange rate regimes. However, when the economic condition is considered from the external perspective measures using trade balance, the magnitude of the impact of both fixed and intermediate regimes appears to be relatively higher for the external economic condition (trade balance) compared to inflation which is a measure for internal economic condition. More importantly, our findings tend to find support in a number of the previous studies. Supporting our finding of declining inflationary in response exchange rate regimes is the study by Ghosh et al. (2002), where it was also shown that there is a negative relationship between fixed exchange rate regime and inflationary pressure. Levy-Yeyaty and Sturzenegger $(2001,2003)$ also support this position by concluding that developing economies with fixed exchange rate regimes are prone to lesser inflationary pressure compared to those operating floating exchange rate systems. Likewise, Husain et al. (2005) concludes that developing nations operating fixed exchange rate regimes tend to experience a lower rate of inflation than those operating flexible or floating exchange rate regimes. On the whole, we found the dynamics of the impacts of exchange rate regimes on economic performance to vary for the different indicators of internal and external economic conditions both in terms of the direction of the relationship, magnitude of the impact of the relationship as well as in terms of the significance of the relationship statistically.

\section{References}

Adeoye, B. W., \& Atanda, A. A. (2010). Exchange Rate Volatility in Nigeria: Consistency, persistence \& Severity Analyses. CBN Journal of Applied Statistics, 2(2), 29-49.

Adesoye, A. B. (2012). Exchange Rate Policy and Price Determination in Nigeria: Testing the long run relevance of PPP Model. European Journal of Humanities and Social, 14(1), 667-683.

Bailliu, J., Lafrance, R., \& Perrault, J. (2003). Does Exchange Rate Policy Matter for Growth? 
International Finance, 6(3), 381-414. https://doi.org/10.1111/j.1367-0271.2003.00123.x

Batini, N., \& Haldane, A. G. (1999). Forward-looking rules for monetary policy. In: Taylor, J.B. (Ed.), Monetary =.Policy Rules. University of Chicago Press, Chicago.Berg, Karam and Laxton, 2006. https://doi.org/10.2139/ssrn.147549

Bleaney, M., \& Francisco, M. (2007). Exchange Rate Regimes, Inflation And Growth In Developing Countries: An Assessment: The B.E. Journal of Macroeconomics, 7(1). https://doi.org/10.2202/1935-1690.1546

Buiter, W. H., \& Jewitt, I. (1981). Staggered Wage Setting With Real Wage Relativities: Variations on a Theme of Taylor. The Manchester School, 49, pp. 211-228, reprinted in W. H. Buiter (Ed.), 1989, Macroeconomic theory and stabilization policy, Manchester: Manchester University Press. https://doi.org/10.1111/j.1467-9957.1981.tb00948.x

Dada, E. A., \& Oyeranti, O. A. (2012). Exchange Rate and Macroeconomic Aggregates in Nigeria. Journal of Economics and Sustainable Development, 3(2), 93-101.

Fuhrer. J., \& Moore, G. (1995). Inflation Persistence. Quarterly Journal Economics, 110(1), 127-159. https://doi.org/10.2307/2118513

Garofalo, P. (2005). Exchange Rate Regimes and Economic Performance: The Italian Experience. Quaderni dell'UfficioRicercheStoriche, 10, 1-50.

Gnimassoun, B. (2015). The Importance of the Exchange Rate Regime in Limiting Current Account Imbalances in Sub-Saharan African Countries. Journal of International Money and Finance, 53, 36-74. https://doi.org/10.1016/j.jimonfin.2014.12.012

Husain, A., Mody, A., \& Rogoff, K. (2005). Exchange Rate Regime Durability And Performance In Developing Versus Advanced Economies. Journal of Monetary Economics, 52(25), 35-64. https://doi.org/10.1016/j.jmoneco.2004.07.001

Levy-Yeyati, E., \& Sturzenegger, F. (2001). Exchange Rate Regimes and Economic Performance. IMF Staff Papers, 7, 62-98. https://doi.org/10.2139/ssrn.263826

Levy-Yeyati, E., \& Sturzenegger, F. (2003). To Float or to Fix: Evidence on the Impact of Exchange Rate Regimes on Growth. American Economic Review, 93(4), 1173-1193. https://doi.org/10.1257/000282803769206250

Mahmood, I., \& Ali, S. (2011). Impact of Exchange Rate Volatility on Macroeconomic Performance of Pakistan. International Research Journal of Finance and Economics, 54-65.

Miles, W. (2006). To float or not to Float? Currency Regimes and Growth. Journal of Economic Development, Chung-Ang University, Department of Economics, 31(2), 91-105.

Nathaniel, A. O., Oladiran, O. I., \& Oladiran, A. K. (2019). Impact of Exchange Rate Regimes on Economic Integration in the ECOWAS. African Journal of Economic Review, 7(2), 42-59.

Omojimite, B., \& Akpokodje, G. (2010). The Impact of Exchange Rate Reforms on Trade Performances in Nigeria. Journal of Social Sciences, 23(1), 53-62. 
https://doi.org/10.1080/09718923.2010.11892811

Raji, R. O. (2013). Impact of Misaligned Real Exchange Rate on Economic Performance: A Case Study of West African Monetary Zone. IOSR Journal of Economic and Finance, 1(6), 56-67. https://doi.org/10.9790/5933-0165667

Reinhart, C. M., \& Rogoff, K. S. (2004). A Modern History of Exchange Rate Arrangements: A Reinterpretation. The Quarterly Journal of Economics, 119(1), 1-48.

https://doi.org/10.1162/003355304772839515

\section{Copyright Disclaimer}

Copyright for this article is retained by the author(s), with first publication rights granted to the journal.

This is an open-access article distributed under the terms and conditions of the Creative Commons Attribution license (http://creativecommons.org/licenses/by/4.0/). 